\title{
ETHICAL CONCERNS REGARDING MALE CIRCUMCISION CULTURE: A SELECTED ETHNICAL GROUP
}

\author{
Cabangile N. Ngwane ${ }^{1}$
}

\begin{abstract}
Traditional cultural practices reflect values and beliefs of members of a community. Culture is an umbrella term, which explains common things people share such as language, customs, beliefs and the way of life. This paper seeks to look at male circumcision culture of a certain indigenous group in South Africa. Male circumcision is associated with ethnic marks, virility, masculinity, rite of passage to manhood however, there are many ethical concerns centering on male circumcision. Hence, this paper seeks to explore the ethical concerns surrounding male circumcision culture of a selected ethnical group in order to contribute to ethical execution of the practice. Little has been done on ethical issues surrounding male circumcision. The fallacy surrounding this phenomenon needs further investigation. The paper intends to contribute to the debate on male circumcision as a way of mitigating HIV/AIDS infections. The Social Norm Theory has been used to explain the phenomenon under study. The constructivist research paradigm enabled the interviewing of participants from the target population, as the study is inductive in nature. The key finding was that they do male circumcision mostly in an unethical way that it also affects women and children. They also do it based on the misconception and the fallacy that they will not get HIV/AIDS.
\end{abstract}

UDC Classification: 314,39; DOI: http://dx.doi.org/10.12955/cbup.v5.1017

Keywords: Male circumcision, culture, fallacy and ethical concerns.

\section{Introduction}

This paper is about ethical concerns centering on the male circumcision culture of a certain ethnical group in South Africa. It is vital to note that male circumcision is associated with ethnic marks, virility, masculinity, rite of passage to manhood. This paper seeks to explore the ethical concerns surrounding male circumcision culture of a selected ethnical group in order to contribute to ethical execution of the ritual. The philosophy underpinning the study is the constructivism research paradigm that informs qualitative research. In order to collect data in the field interviews were conducted at Mpolweni informal settlement in the Reservoir Hills. The Social Norm Theory was used to explain the phenomenon under study better.

Figure 1: Male circumcision model

\section{Constructivism research paradigm}

The worldview underpinning the study is the constructivism research paradigm. According to this paradigm "the nature of social constructions requires individual constructions to take place through the interaction between the researcher and participants" as (Mackenzie \& Knipe, 2006) asserts. I chose

\footnotetext{
${ }^{1}$ Faculty of Arts and Design, Durban University of Technology, cabangile12@hotmail.com
} 
this paradigm because it is a philosophy to qualitative research and I wanted to "utilize open-ended questions to allow participants to share their views" as Creswell (2014) confirms. The case study was conducted in the Reservoir Hills informal settlements focusing at Mpolweni as a target population. I interviewed 12 participants ( 2 mothers, 3 fathers and 7 initiates). I conducted interviews because I depended on the views of the participants regarding the male circumcision phenomenon. A thematic analysis was used. Research ethical rules were adhered to including seeking participant consent, avoiding plagiarism, fabrication and falsification of data, etc. Consequently, the results are valid, credit and trustworthy as they are based on theoretical and empirical data.

\section{Results}

In addressing the objective of the research, it was discovered that custodians of circumcision do not only perform it unethically; but they also break the law. They violate the standard principles of surgery by circumcising babies without their consent and without medical justification. They harass women based on the myth of cleansing, which is sexual harassment and women abuse. They also believe that they do not contract HIV/AIDS because of circumcision. Consequently, when they get sick because of AIDS they attribute their sickness to witchcraft. All males do circumcision because they are afraid of the stigma as they will be perceived as boys (not as men) for the rest of their lives. They believe that they will gain respect if they undergo this process and become the real men. The government needs to engage various stakeholders so that they could work together through the participatory mode in order to avoid unethical practices and complications. The awareness campaign is necessary to educate community members about the advantages and disadvantages of the routine circumcision.

\section{Discussion}

It is important to remember that the paper sought to explore the ethical concerns surrounding male circumcision culture of a selected ethnical group in order to contribute to the ethical execution of the practice. The major ethical concern regarding male circumcision is circumcision of babies that violates standard principles of surgery. This is performed with no medical indication and reason. According to the standard surgery principle, no operation should be done when there is no disease. In addition, an operation needs to be done if it can be substantiated that its risk cannot be equated to the risk of the disease. Furthermore, Hutson (2003) concurs by positing that even if patients have diseases, dangerous procedures can seldom be justified if the risks are higher than the disease. The routine circumcision is done when there is no complication or disease; therefore, its risks are not balanced against the disease risks. Szabo and Short (2000) further assert that the cost-benefit analysis approach renders routine circumcision unnecessary, as it is not justified by the medical indications. Participants made it clear that they will not allow medical practitioners to undermine their culture by posing some unnecessary threats and warnings. It is clear that the people feel strong about their culture and customs. They may feel strong about their culture but routine circumcision goes against the standard principles of surgery and when complications prevail in a process, they consult the medical practitioners. It will be crucial to run an awareness campaign that would not criticise their practice.

There have been some cases of men who experienced surgical complications from childhood because of the circumcision resulting in inadequate sexual function. Stein (2008) confirms this by saying that circumcision reduces enjoyment in lovemaking. Moreover, Laumann et al. (1997) contend that a serious complication is when the tip of the penis is cut accidentally or excessive cutting of the penile shaft skin causing deformity. Such people end up having gender issues because of losing part of their penis. This could be avoided by abolishing the practice. This angered participants. They felt that this undermines their capability. They perceived them as the people who have no potential and who are careless. The medical practitioners need to work with traditional people to avoid victimisation of initiates. Apportioning blame will not bring the solution. Collaboration will help. The people are protective of their culture as the social norm theory explains

The male circumcision practice affects women in different unethical ways. The practice is associated with the cleansing myth that affects women adversely. Maluleke (2012) confirms that civil society organisations in KwaZulu-Natal, Limpopo and the Eastern Cape are unhappy about this cleansing of newly circumcised initiates. In addition, Gwandure (2011) explains that the cleansing ritual occurs when the initiates have to get a woman or even a widow to gang rape as a cleaning procedure. The participants do not like to talk much about circumcision in general because of a warning that women 
should not hear anything about this ritual. They did not want to confirm or refute this myth. The Zulu speakers strongly believe in Ubuntu and this myth is absolutely against Ubuntu. Moreover, it violates the law, which means it is the criminal act. Furthermore, it is highly unethical. It also violates the United Nations Declaration Charter that promotes equal human rights and human dignity. The Social Norm theory states that those who break social norms face consequences, those who commit this abusive act against women should face punishment. This myth needs to be investigated and be exposed.

There is a fallacy that male circumcision protects circumcised men from contracting the HIV. However, the Doctors opposing male circumcision (2008) confirm that there is a likelihood that circumcision has a potential of decreasing female-to-male HIV transmission. As a result, medical male circumcision has become part of comprehensive strategies to prevent the HIV infection. Furthermore, Talbott (2007) explains that studies conducted in Africa (South Africa, Uganda and Kenya) discovered that non-circumcised men contract the virus more quickly than circumcised ones. The studies further reveal that it could be because the circumcised men abstain for a certain period after their circumcision. It was sad to discover that participants in the field had a strong misconception that they would not get the virus because of the circumcision or their partners have been circumcised. Consequently, when they get sick because of the virus they always blame witchcraft. They do not see themselves having the virus. They refuse to consume any form of medication such as anti-retroviral or tuberculosis tablets.

There is belief that the male circumcision is likely to reduce HIV infection by the use of female-tomale heterosexual transmission method. Glick (2005) maintains that the male-to-female transmission risk is extremely higher than of female-to-male transmission. Glick further explains that the means of partial prevention is a futile exercise as it prevents men at the expense of women. There is no indication that the male circumcision could protect women from the HIV infection. Moreover, Spearman (2006) concurs by asserting that circumcised males protect themselves from HIV while putting their partners at risk. However, Doctors opposing male circumcision (2008) contend that the circumcised men may still contract the virus and pass it on to their sexual partners. The participants stated that their partners will not get the HIV because they will not get it. This confirms their ignorance, fallacy and misconception. This confirms the Social Norm Theory as it contends that they perform the male circumcision practice because it is a cultural norm and run away from a stigma. They are also afraid of the costs of deviant behavior. Therefore, this means that the male circumcision ritual protects men, but not women. It is unethical to protect a certain group at the expense of the other. Although the men are not $100 \%$ immune.

Performing circumcision at any age should be done safely in order for it to be ethical. Safe circumcision is expensive. Rennie et al. (2007) maintain that fee estimates differ, but the cost could prevent this practice to those who are poor in developing countries. To avoid this problem, it could be a good idea to perform this ritual in clinical settings. In addition, Cassell et al. (2006) explain that the less privileged groups could only access cheaper circumcision that exposes them to greater complication and risks as well as the risk of HIV infection. This forces them to go to self-appointed circumcisers who render dubious services at cheaper prices. Furthermore, some circumcisers commercialize the ritual by charging exorbitant prices. This side-lines the poverty-stricken group as it cannot afford the ritual. The participants explained that even clinics charge fees. They mentioned that if it is done in clinics it would not serve the purpose because they learn various manhood practices at the initiation school. If they could not go to initiation school, they will be insulted and they will be viewed as boys forever. Their peers will undermine them. This confirms the Social Norm Theory as it says that they fear the stigma and they want to be relevant.

\section{Social norm theory}

The value of circumcision is based on culture. The primary purpose of male circumcision is a social reason rather than a medical one. The cultural norm supporting male circumcision has an impact on how parents decide on the phenomenon. Waldeck (2003) asserts that the dynamics of circumcision may not be able to reduce its rate dramatically with no legal interventions. Perceiving circumcision as good or bad should be left for parents to decide. Parents circumcise their children because of cultural norms rather than medical reasons. Furthermore, Waldeck (2003) explains that norms regulate behavior because of associated costs of failure to adhere. As a result, people who do not comply could 
experience the self-imposed guilt. In addition, parents have their children circumcised so that they do what their peers do because non-circumcision is a stigma. Most importantly, social norms have costs for deviant behavior. Moreover, social norms affect the way the people think, understand and process information. Consequently, educating the people about the advantages and disadvantages of circumcision may not lead to the decline of circumcision. If one could keep warning the parents about circumcision, they might resent the information. They may despise a person who challenges their ancestral culture. They may ignore the warning and costs.

\section{Conclusion}

The paper intended to investigate how a certain ethnic group in South Africa circumcises boys. To conduct the research interviews had been conducted in the Mpolweni informal settlement in the Reservoir Hills suburb. The study discovered various unethical practices that occur during the process. The misconception and fallacy have been addressed.

\section{Acknowledgements}

My greatest gratitude goes to the National Research Foundation for its continuous support.

\section{References}

Cassell, M., Halperin, D \& Shellton. (2006). Risk Compensation: The Achilles' Heel of Innovations in IV Prevention. BMJ. 332605-607.

Creswell, J.W. (2014). Research Design: Qualitative, Quantitative and Mixed Methods Approaches,

$4^{\text {th }}$ edition. London. Sage Publications, Inc. 1-242.

Doctors opposing male circumcision (2008). The Use of Male Circumcision to Prevent HIV Infection.

United States of America. Seatle. http://www.doctorsopposingcircumcision,org/info.HIVStatement.html.

Glick, L.B. (2005). Marked in Your Flesh: Circumcision from Ancient Judea to Modern America.

New York. Oxford University Press.

Gwandure, C. (2011). Ethical Concerns of Using Medical Male Circumcision in HIV Prevention,

Educational Psychologist, HPCSA. Johannesburg. SAJBL. 4(2)

Hutson, J.M. (2003). Circumcision: A Surgery Perspective. Victoria. BMJ Open.

Laumann, E.O., Masi, C.M. \& Zuckerman, E.W. (1997). Circumcision in the United States:

Prevalence, Prophylactic Effects and Sexual Practice. JAMA. 2771052-157.1057. (Pubmed).

Mackenzie, N. \& Knipe, S. (2006). Research Dilemmas, Methods and Methodology. Issues in

Educational Research, 16. http://www.iier.org.au/iier16/mackenzie.html.

Maluleke, M.J. (2012). Culture, Tradition, Law and Gender Equality. PotchestroomSAFL11.

Rennie, S., Muula, A.S.\& Westreich, D. (2007). Male Circumcision and HIV Prevention. Journal of

Medical of Medical Ethics. 33 (6), p. 357-361.

Spearman, P. (2006) Current Progress in the Development of HIV Vaccines. Current Pharm Des, 12 (9).

Stein, S. (2008). When Falls the Colisem. A Journal of American Culture. Philadephia.

http://whenfallsthecoliseum.com/2008/1030/circumcision-jewish-conspiracy-theory/

Szabo, R., Short,R.V. (2000). How Does Male Circumcision Protect against HIV Infection.

BMJOpen.

Talbott, J.R. (2007). Size Matter: The Number Prostitutes and the Global HIV/AIDS Pandemic.

PlosOne.

Waldeck, S.C. (2003). Social Norm Theory and Male Circumcision: Why Parents Circumcise?

Amercian Journal of Bioethics. 3(2), p. 56-60 